\title{
SEPARATION OF CAPSULATE AND NON-CAPSULATE BACTEROIDES FRAGILIS ON A DISCONTINUOUS DENSITY GRADIENT
}

\author{
Sheila Patrick AND J. H. Reid \\ Department of Microbiology and Immunobiology, The Queen's University of Belfast, \\ Grosvenor Road, Belfast BT12 $6 B N$
}

\begin{abstract}
SUmmary. A discontinuous density gradient procedure was used successfully to separate capsulate and non-capsulate cells of strains of Bacteroides fragilis. Bacteria from the capsulate fraction retained their capsules on subculture, but non-capsulate cells reverted to the mixed phenotype.
\end{abstract}

\section{INTRODUCTION}

Considerable emphasis has been placed on the importance of the polysaccharide capsule of Bacteroides fragilis as a virulence determinant (Kasper et al., 1977). In studies with rats, the polysaccharide capsule has been shown to promote the formation of intra-abdominal abscesses similar to those found in human infection (Onderdonk et al., 1977).

A homogeneous population of bacteria is necessary to investigate the selective advantage of the capsule in pathogenesis. Variation in the proportion of capsulate and non-capsulate cells within individual Bacteroides cultures (Babb and Cummins, 1978) and instability of capsule production by $B$, thetaiotaomicron (Burt et al., 1978) have been reported. Booth et al. (1979) reported that capsulate $B$. fragilis were resistant to bacteriophage infection and suggested that this might be used to obtain a capsulate population. Percoll density gradients have been used for the separation of prokaryotic cells, for example, to synchronise cell division (Dwek, Kobrin and Grossman, 1980) and to separate Escherichia coli possessing colonisation factor antigen 1 (Giesa et al., 1982). In this paper we report the use of a discontinuous Percoll density'gradient to separate capsulate and non-capsulate $B$. fragilis.

\section{MATERIALS AND METHODS}

Bacterial strains. B. fragilis NCTC9343 was supplied by the Department of Bacteriology, University of Edinburgh Medical School and B. fragilis ATCC23745 by the American Type Culture Collection, Rockville, MD. B. fragilis NCTC10584 was a departmental stock culture.

Culture methods. Bacteria were grown in defined broth (van Tassell and Wilkins, 1978), the basal medium of Deacon, Duerden and Holbrook (1978) or on plates of lysed human-blood agar (LHBA). Cultures were incubated at $37^{\circ} \mathrm{C}$ in an atmosphere of $90 \% \mathrm{H}_{2}$ and $10 \% \mathrm{CO}_{2}$ in anaerobic jars with two catalyst sachets per jar.

Microscopy. The presence of capsules was determined by light microscopy with Indian ink and eosin-carbol fuchsin negative staining (Cruickshank, 1965). The proportion of capsulate cells was determined by random field counts of eosin-carbol fuchsin stained preparations under a $\times 100$ oil-immersion objective. All determinations were done with late exponential-phase cultures containing approximately $10^{8} \mathrm{cfu} / \mathrm{ml}$.

Density gradient centrifugation. Percoll (a colloidal sol of polyvinylpyrrolidone-coated silica particles; Pharmacia Fine Chemicals Inc., London) is supplied sterile. A stock solution, isosmotic with physiological saline, was prepared by diluting with $1.5 \mathrm{M} \mathrm{NaCl}$ in a ratio of $9: 1$. The $p \mathrm{H}$ of this solution was adjusted to 7.0 with $1 \mathrm{M} \mathrm{HCl}$. Solutions of $20,40,60$ and $80 \%$ Percoll were prepared by further dilution with $0.15 \mathrm{M} \mathrm{NaCl}$. 
A 2-ml volume of each of these solutions was layered into a test tube to produce a step gradient with $80 \%$ Percoll at the bottom and the $20 \%$ solution at the top. A broth culture of the test organism $(2.5 \mathrm{ml})$ was applied to the top of the $20 \%$ layer and the gradient centrifuged at $2600 \mathrm{~g}$ for $20 \mathrm{~min}$ in a bench centrifuge. After centrifugation the bands were removed with sterile 2-ml syringes fitted with long needles. Bacteria from the gradients were subcultured without further processing.

\section{RESULTS}

Approx. $17 \%$ of the cells in the B. fragilis ATCC23745 culture produced capsules greater than the width of the cell in size when grown in the defined medium of van Tassel and Wilkins (1978). Capsules of the same dimension were observed in ruthenium red stained preparations by electron microscopy. Fewer than $1 \%$ of the cells of $B$. fragilis strains NCTC10584 and NCTC9343 produced capsules of similar size when grown under the same conditions. Capsules produced in the basal medium or on LHBA plates were smaller and difficult to assess because the eosin-carbol fuchsin stain tended to shrink from the edge of the cell to produce a bright halo similar to that of a small capsule.

After centrifugation of cultures in defined medium on a Percoll density gradient, cells with
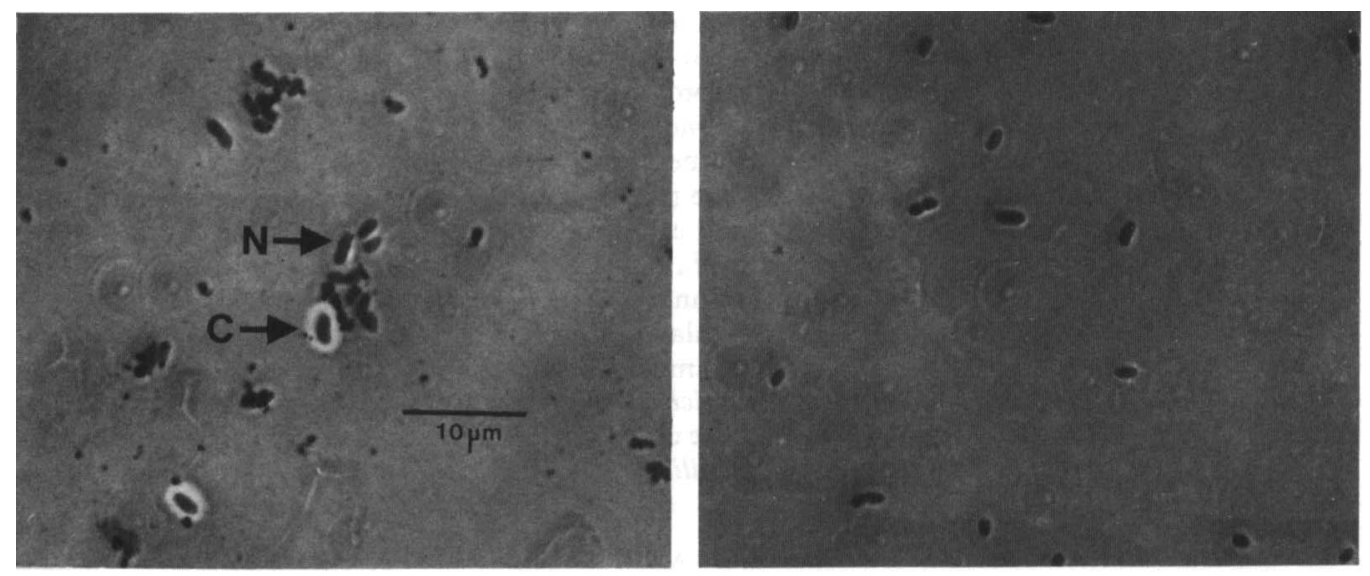

a

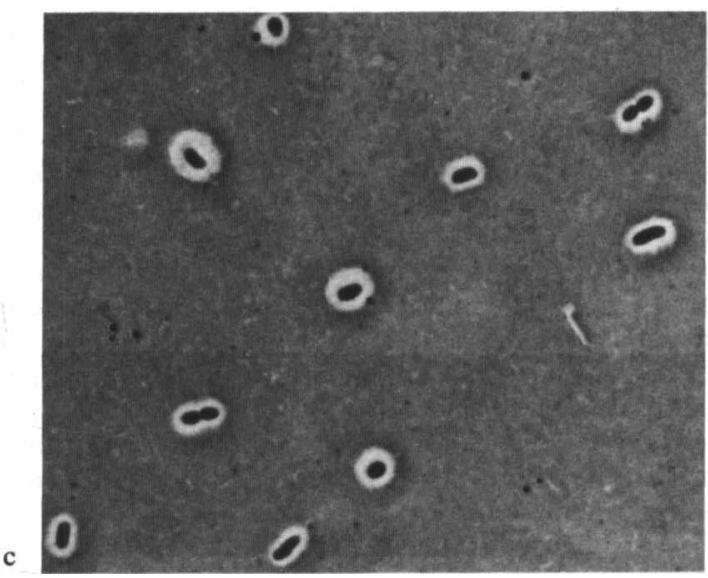

FIGURE. Photomicrographs of Bacteroides fragilis ATCC23745 grown in defined medium: a, culture before density gradient centrifugation; $b$, cells harvested from top of Percoll gradient after centrifugation; $c$, cells harvested from interface between $60 \%$ and $80 \%$ Percoll layers after centrifugation; $C=$ capsulate cell; $\mathbf{N}=$ non-capsulate cell. 
large capsules remained on top of the $20 \%$ layer and non-capsulate cells were concentrated at the $60-80 \%$ interface (figure). Most of the cells of $B$. fragilis strains ATCC23745 and NCTC10584 were found at either the $0-20 \%$ or the $60-80 \%$ interface. However, B. fragilis NCTC9343 produced additional bands at the $20-40 \%$ and $40-60 \%$ interfaces. These bands were formed by bacteria bearing capsules of graded sizes.

In subcultures of bacteria from the top layer of the density gradient, $90 \%$ of the cells of $B$. fragilis NCTC10584 and $99 \%$ of the cells of $B$. fragilis strains ATCC 23745 and NCTC 9343 were capsulate. Further subcultures of $B$. fragilis ATCC23745 were examined. Capsulate bacteria represented $95-100 \%$ of the total number of cells for the first three subcultures, after which the proportion of capsulate cells gradually diminished. Subculture of the 'non-capsulate' fractions resulted in an immediate return to the initial distribution of capsulate and non-capsulate cells.

\section{Discussion}

The method described produced homogeneous suspensions of cells with and without capsules. The capsulate fraction of B. fragilis strains ATCC23745 and NCTC9343 remained capsulate after subculture into defined broth and could be used in further studies. A proportion of cells of the non-capsulate fraction produced capsules when subcultured. This instability restricts the use of the non-capsulate fraction to investigations in aerobic conditions. In these conditions growth and biosynthesis of the capsule are prevented although viability of the phenotypically non-capsulate population is maintained. This useful technique has allowed us to proceed with in-vitro studies on the interaction of capsulate and non-capsulate $B$. fragilis with granulocytes and serum.

\section{REFERENCES}

BabB, J. L. AND Cummins, C. S. 1978. Encapsulation of Bacteroides species. Infection and Immunity, 19, 1088-1091.

Booth, S. J., VAN TASSEll, R. L., Johnson, J. L. AND Wilkins, T. D. 1979. Bacteriophages of Bacteroides. Reviews of Infectious Diseases, 1, 325-336.

Burt, S., Meldrum, S., Woods, D. R. AND Jones, D. T. 1978. Colonial variation, capsule formation, and bacteriophage resistance in Bacteroides thetaiotaomicron. Applied and Environmental Microbiology, 35, 439-443.

CRUiCKSHANK, R. 1965. Medical Microbiology: a guide to the laboratory diagnosis and control of infection, 11th ed., E. \& S. Livingstone Ltd, Edinburgh, pp. 657-660.

Deacon, A. G., Duerden, B. I. AND Holbrook, W. P. 1978. Gas-liquid chromatographic analysis of metabolic products in the identification of Bacteroidaceae of clinical interest. Journal of Medical Microbiology, 11, 81-99.

Dwek, R. D., Kobrin, L. H., Grossman, N. AND Ron, E. Z. 1980. Synchronization of cell division in microorganisms by Percoll gradients. Journal of Bacteriology, 144, 17-21.

GIESA, F. R., ZAJAC, I., BARTUS, H. F. AND ACTOR, P. 1982. Isopycnic separation of Escherichia coli cultures possessing colonisation factor antigen 1. Journal of Clinical Microbiology, 15, 1074-1076.

Kasper, D. L., Hayes, M. E., Reinap, B. G., Craft, F. O., Onderdonk, A. B. ANd Polk, B. F. 1977. Isolation and identification of encapsulated strains of Bacteroides fragilis. Journal of Infectious Diseases, 136, 75-81.

Onderdonk, A. B., Kasper, D. L., Cisneros, R. L. AND Bartlett, J. G. 1977. The capsular polysaccharide of Bacteroides fragilis as a virulence factor: comparison of the pathogenic potential of encapsulated and unencapsulated strains. Journal of Infectious Diseases, 136, $82-89$.

VAN TASSELL, R. L. AND WILKINS, T. D. 1978. Isolation of auxotrophs of Bacteroides fragilis. Canadian Journal of Microbiology, 24, 1619-1621. 